\title{
The Level of Awareness of the Coronavirus Pandemic and Its Prevention for Students With Learning Difficulties in the State of Kuwait
}

\author{
Nawaf M. AlThafiri ${ }^{1}$, Ahmed M. AlSaeedi ${ }^{1}$ \\ ${ }^{1}$ Public Authority for Applied Education, Faculty of Basic Education, Kuwait \\ Correspondence: Dr. Ahmed M. AlSaeedi, Associate Professor of Special Education, College of Basic Education, The \\ Public Authority for Applied Education, Kuwait.
}

Received: March 2, 2021

doi:10.11114/jets.v9i4.5180
Accepted: April 11, $2021 \quad$ Online Published: April 18, 2021

URL: https://doi.org/10.11114/jets.v9i4.5180

\begin{abstract}
This study aimed to identify the level of awareness of the emerging coronavirus pandemic and prevent infection among (18) students with learning difficulties in the State of Kuwait. The study applied a scale prepared by researchers in the period of 12 th till the 17th of May 2020 . The alpha was between $(0.74-0.76)$, indicating that the scale has a high degree of validity and reliability. The results showed high levels of awareness and prevention among the study sample, as their awareness rate reached $83 \%$, while the rate of infection prevention reached $88 \%$, while as a whole, the model showed the rate of $87 \%$ on the scale.
\end{abstract}

Keywords: awareness of coronavirus, students with learning difficulties

\section{Introduction}

December 2019, the Chinese city Wuhan recorded the first infections of the emerging coronavirus, which causes COVID-19. At the beginning of the year 2020 and with a period of about a month, this virus quickly spread to almost all countries of the world. Accordingly, this virus was considered a global pandemic and a global epidemic according to the World Health Organization's declaration, as countries started to record cases of infections and deaths in this disease in an accelerated way and in huge numbers. The number of injuries at the end of this study on $27 / 5 / 2020$ was approximately 5687,662 , the death toll was approximately 353,365 , and the number of people who recovered 243,1160 cases. Since the registration of this disease as a universal epidemic, the countries of the world have taken health measures and preventive measures in an attempt to reduce the spread of this epidemic, and these measures and precautions vary from one country to another according to the health, economic and social conditions. The emergence of this virus has resulted in paralysis in all aspects of public life for the countries of the world, which resulted in effects on various sectors in human life, including social, psychological, and economic, health and others, and these effects may continue for an unknown period. Everyone in the world has been repeating the phrase "life after Corona is not like life before Corona and the world we knew will change".

The World Health Organization (WHO) has indicated everything related to this epidemic and the answer to many questions about this pandemic and this disease, Corona viruses are a large family of viruses that may cause disease to animals and humans. A number of corona viruses are known to cause respiratory infections in humans cause respiratory infections that range from common cold to more severe diseases such as Middle East Respiratory Syndrome and Severe Acute Respiratory Syndrome (SARS). The recently discovered Corona virus causes Corona COVID-19.

COVID-19 is a contagious disease caused by the recently discovered corona virus. There was no knowledge of the existence of this virus and this emerging disease until the outbreak in the Chinese city Wuhan in December 2019. The most common symptoms of this disease are fever, fatigue and dry cough, and some patients may suffer from pain and aches, nasal congestion, runny nose, sore throat, or diarrhea, and these symptoms are usually mild and start gradually, and on the other hand some people become infected without showing any symptoms and without even feeling sick. Most people for about $(80 \%)$ recover from the disease without the need for special treatment, and the severity of the disease increases in approximately one person out of every six infected people, as they suffer from breathing difficulty. Elderly people and people with major medical problems such as high blood pressure, heart disease, or diabetes are more likely to suffer.

People become infected with Covid-19 disease through other people infected with the virus, the disease can be 
transmitted from person to person through small droplets that are scattered from the nose or mouth when an infected person coughs or sneezes, and these droplets fall on the objects and surfaces surrounding the person, others can then be injured when they touch these objects or surfaces and then touch their eyes, nose, or mouth, and people can be injured if they breathe the droplets that come out of the person suffering from the disease with his or her cough or exhale. It is therefore important to keep the patient at least one meter away.

To maintain your health and protect others from the spread of the virus, do the following:

- Clean your hands regularly by rubbing them with an alcohol-based hand sanitizer or by washing them with soap and water.

- Keep a distance of at least one meter between yourself and anyone who is coughing or sneezing.

- Avoid touching your eyes, nose, and mouth.

- Ensure that you and those around you follow good respiratory hygiene practices, which means that you cover your mouth and nose with your bent elbow, a tissue when coughing, or sneezing, and then get rid of the used tissue immediately.

- Stay home if you feel sick, and if you have a fever, cough and difficulty breathing, seek medical attention and contact the caregiver before leaving the house, and follow directions from local health authorities.

- Stay up to date on the latest developments about COVID-19, and follow any advice given by your healthcare provider, national and local public health authorities, or your employer on how to protect yourself and others from the disease.

- If you started to feel unwell, stay home until you recover, even if your symptoms are mild, such as a headache or a slight runny nose.

- If you have a fever, cough and breathing difficulty, seek medical advice immediately. You may have a respiratory infection or other severe illness. Call before going to the caregiver and tell him if you have traveled or had contacted with any travelers recently.

According to the announcement of the Kuwaiti Ministry of Health on 2/25/2020, the State of Kuwait recorded the first infections with the Coronavirus for three people coming from abroad, and accordingly the government of the State of Kuwait took a set of preventive and health measures and precautions to limit the spread of the virus, as follows:

- 1/3/2020 suspension of studies in all schools, institutes and universities until further notice.

- 12/3/2020 rest for all workers in the government and private sectors, except for those working in the front lines to confront this pandemic.

- 3/22/2020 announcing a partial curfew daily (from $5 \mathrm{pm}$ to $4 \mathrm{am}$ ) on all regions of the country.

-6/4/2020 amending the partial curfew dates to become daily (from 5 pm to 6 am) and imposing a total ban on some areas, as they are considered hotspots for the spread of the virus.

-10/5/2020 imposing a total ban on all regions of the country for a period of twenty days.

The government, represented by the Ministry of Health, has also spread health awareness among community members through various media, by spreading the culture of introducing this virus, ways to prevent it and how to deal with it since the beginning of the crisis, by preserving social distancing and wearing masks and gloves, and it is worth mentioning that the State of Kuwait until 27/5/2020 has recorded 23,267 cases, including 175 deaths and 7,946 recoveries from the virus. During the current events prevailing over the entire world due to the emerging Corona virus pandemic, and what this pandemic has caused of confusion in our daily life, there is a group of society that must be shed light on and to know the extent of their awareness and knowledge of what is going on around them these days, namely, those with learning difficulties. The group suffers from many problems as a result of the learning difficulties, such as developmental, academic or social learning difficulties.

People with learning difficulties of all ages, severity and type of difficulty suffer from deficiencies in social aspects such as social competence and social skills, and this deficiency may be due or it may be related to the developmental or academic difficulties they suffer from. (Al Thafiri, 2012)

Developmental or academic learning difficulties are related to social aspects of the individual or to social learning difficulties, and the results of studies in this field confirm the existence of a correlational relationship between the different types of learning difficulties, and such a link between these difficulties leads to the occurrence of multiplying problems for many people with learning difficulties. The influence of the individual's developmental side effects its academic and social aspects, as well as the existence of problems on the academic side that affect the social aspect, as 
the relationship between these types is reciprocal. (Al Thafiri, 2014), We review a set of previous studies in the field of learning difficulties to shed light on the many different types of these difficulties, in order to show the size of this problem and its complexities among people with learning difficulties, as well as the amount of deficiencies they suffer from, whether they are academic, developmental, social or psychological deficiencies.

The study of Nirit et al. (2005) concluded the suffering of people with learning difficulties from their inability to form the process of social behavior and the complex emotional concept, such as: the complex understanding and internal feelings compared to the ordinary. This study helps educators and trainers better understand the emotional background for their behaviours. Al Thafiri study (2010) aimed to compare the social skills of students with learning difficulties and their ordinary counterparts. The results revealed that there are statistically significant differences between students with learning difficulties and ordinary students in favor of ordinary students. These results show that learning difficulties can affect the way one responds to life experiences and events. The study of Manfredi et al. (2012) aimed to identify the differences between ordinary and people with learning difficulties in visual perception skills, and the study resulted in differences in visual perception skills in favor of ordinary students, and the study also resulted in a direct relationship between perception skills and severity of learning difficulty. So reduced perception does limit an individual's ability to cope with difficult or different situations such as the current COVID-19 crisis. The study of Schum et al. (Schum et al., 2012) also aimed to identify visual, motor and auditory perception skills among those with learning difficulties, and the study resulted in a relationship between these skills and academic learning difficulties, and the results also revealed varying differences between these skills and the type of academic learning difficulty. The results of this study reinforce the above study results, relating learning difficulty with different levels of perceptual skills. Al Thafiri study (2015) aimed to identify the psychological needs of people with learning difficulties, and the results of the study resulted in the emergence of psychological needs of people with developmental learning difficulties more than ordinary people. The results of this study also reinforce the theory that people with learning difficulties will probably have more needs than those of their ordinary fellow colleagues. Al Thafiri study (2016), which aimed to study the relationship between developmental learning difficulties and academic learning difficulties on one hand, and social and emotional learning difficulties on the other hand, and the results showed an increase in correlation coefficients between types of difficulties reaching more than 0.9. These results are quite interesting; it is important that we understand the emotional reflections of facing difficult situations and how this category of the society reacts. Based on the above study results Al Thafiri and Abbas (2017) conducted another study that aimed to identify psychological compatibility among people with learning difficulties. The results of this study showed statistically significant differences between the average scores of students in all dimensions of psychological compatibility in favour of ordinary students and the results also showed no differences between the sexes. This is consistent with the fact that learning difficulties are not the only difficulties these people face in life. It affects their psychology and emotional balance. Al Thafiri study (2018) aimed to identify psychological needs (competence, independence, belonging) and their ability to predict developmental learning difficulties. The results showed statistically significant differences between people with developmental learning difficulties and normal ones in favour of ordinary people with psychological needs. This goes in coherence with the previous studies relating learning difficulties with more profound side-difficulties ranging from perceptual, emotional, psychological, behavioural and many other aspects.

\section{The Study Problem}

As a result of the state of learning difficulties experienced by some groups of society, people with learning difficulties have an obstacle to their education and their appropriate acquisition of knowledge, and consequently disturbance in the processes of perception, attention and memory. They also have deficiencies in social and psychological skills, as shown in the literature of the field and previous studies and the emergence of a global problem represented by the Covid-19 pandemic. The problem of the current study is crystallized in an attempt to identify the level of awareness of this group of this pandemic, by asking the following question: What is the level of awareness of people with learning disabilities of all levels (mild, moderate or severe) about the Corona virus pandemic and methods of prevention, and how much assistance do they need in order to be able to successfully apply all the necessary preventative measures?

\section{Purpose of the Study}

This study aimed to identify the level of awareness of the Corona virus pandemic and methods of preventing the infection (washing and sanitizing hands and face, social distancing, avoiding touching surfaces unnecessarily, etc.) with this virus among students with learning difficulties in upper grades in the State of Kuwait.

\section{The Importance of Studying}

The novelty of the current study is the subject of research by virtue of the conditions in which the world lives resulting from the Coronavirus pandemic, which makes this particularly important for this study, which can be represented by the following points: 
- Providing new data and information in the field of learning difficulties, by studying this category in light of the spread of the Coronavirus pandemic.

- Contribute to highlighting the health of people with learning difficulties and methods of safety and security from diseases, epidemics, disasters and others.

- Spreading a healthy culture among community members in general and those with learning difficulties in particular.

- Documentation of events accompanying the spread of the Coronavirus pandemic.

\section{Study Approach}

The current study adopted the descriptive approach to suit the study procedures, as the study aimed to collect data and information on people with learning difficulties in light of the spread of the Corona pandemic in the State of Kuwait.

\section{The study sample}

The study sample amounted to 18 students with learning difficulties in upper grades, registered in the academic year 2019/2020 at the Sultan Educational Academy for People with Learning Difficulties in the State of Kuwait, who answered the scale from 12-17 / 5/2020 by designing a special online link (age range between 14-18 years).

\section{Study Tool}

Awareness and Prevention Scale (Developed by the researchers)

The two researchers designed the scale to recognize the level of awareness and prevention among students with learning difficulties from the Coronavirus pandemic, based on health information available from the World Health Organization, the Ministry of Health in the State of Kuwait, and the decisions of the Kuwaiti Cabinet, and the scale included 27 phrases that represent two dimensions, the first dimension is the awareness of the virus, it contains 15 phrases (1-15), and the second dimension is the prevention of infection with the virus and it contains 12 phrases (1627), and the response on the scale is closed with yes or no, represented by degrees zero and one, so that the highest score is 27 and the lowest is zero. It determines the awareness and prevention for the student based on the following percentages: $\bullet 90 \%$ and above is a very high level, $\bullet 80 \%$ - less than $90 \%$ is a high level, $\bullet 70 \%$ - less than $80 \%$ average level. $60 \%$ - less than $70 \%$ is a low level, $50 \%$ - less than $60 \%$ is a very low level. Table (1)Shows the scale phrases, showing the positive and negative expressions and the distribution of scores.

Table 1. Table title (Correct the scale)

\begin{tabular}{clcc}
\hline Statement & Yes & No. \\
\hline 1 & Corona is an infectious disease & 1 & 0 \\
2 & Corona is a new disease & 1 & 0 \\
3 & Corona is a virus & 1 & 0 \\
4 & The number of viruses is small & 0 & 1 \\
5 & Viruses can be seen by eye & 0 & 1 \\
6 & Everyone is at risk of contracting Corona & 1 & 0 \\
7 & Corona stays in the body forever & 0 & 1 \\
8 & Corona is transmitted through the air & 0 & 1 \\
9 & Corona is transmitted by sneezing & 1 & 0 \\
10 & Corona leads to the death of every infected person & 0 & 1 \\
11 & You can recognize a person with corona & 0 & 1 \\
12 & You can catch corona without having symptoms & 1 & 0 \\
13 & There is a vaccine against Corona & 0 & 1 \\
14 & Coronavirus patient needs a long time to recover & 0 & 1 \\
15 & Heat, sneezing and shortness of breath are symptoms of Corona & 1 & 0 \\
16 & There is a treatment for Corona & 0 & 1 \\
17 & Corona can be prevented & 1 & 0 \\
18 & Distance from people, to prevent corona & 1 & 0 \\
19 & The curfew helps spread Corona & 0 & 1 \\
20 & A person's strong immunity kills corona & 1 & 0 \\
21 & Wearing a mask to prevent corona & 1 & 0 \\
22 & The body's immunity can be raised & 1 & 0 \\
23 & Fast food increases the body's immunity & 0 & 1 \\
24 & Sterilization of materials to prevent corona & 1 & 0 \\
25 & Remove the mask and wear it more than once to prevent corona & 0 & 1 \\
26 & Washing hands with soap and water well, to prevent corona & 1 & 0 \\
27 & Vegetables and vitamins increase the body's immunity & 1 & 0 \\
\hline & & &
\end{tabular}




\section{The Validity and Reliability of the Scale}

The validity of the scale was calculated by extracting the structural validity coefficients for the two dimensions of the scale with the total score of the scale. As for the reliability of the scale, the alpha reliability coefficient was extracted for the scale paragraphs, and Table No. (2) Shows the structural validity coefficients for the two dimensions of the scale with the total score of the scale.

Table 2. Table title (Structural validity correlation coefficients)

\begin{tabular}{lc}
\hline \multicolumn{1}{c}{ Dimension } & $\begin{array}{c}\text { Correlation } \\
\text { coefficient }\end{array}$ \\
\hline The first is awareness & 0.74 \\
The second is prevention of injury & 0.76 \\
\hline
\end{tabular}

It is evident from the previous table that there are high correlation coefficients between the scores of the two dimensions of the scale and the overall score of the scale, which indicates that the scale has a high degree of validity. As for the stability of the scale, Table No. (3) Shows the alpha stability coefficient for the scale items.

Table 3. Table title (Alpha stability factor)

\begin{tabular}{lc}
\hline \multicolumn{1}{c}{ Statement } & $\begin{array}{c}\text { Alpha } \\
\text { coefficient }\end{array}$ \\
\hline Corona is an infectious disease & 0.77 \\
Corona is a new disease & 0.78 \\
Corona is a virus & 0.75 \\
The number of viruses is small & 0.76 \\
Viruses can be seen by eye & 0.76 \\
Everyone is at risk of contracting Corona & 0.72 \\
Corona stays in the body forever & 0.78 \\
Corona is transmitted through the air & 0.75 \\
Corona is transmitted by sneezing & 0.75 \\
Corona leads to the death of every infected person & 0.72 \\
You can recognize a person with corona & 0.78 \\
You can catch corona without having symptoms & 0.74 \\
There is a vaccine against Corona & 0.76 \\
Coronavirus patient needs a long time to recover & 0.75 \\
Heat, sneezing and shortness of breath are symptoms of Corona & 0.74 \\
There is a treatment for Corona & 0.73 \\
Corona can be prevented & 0.75 \\
Distance from people, to prevent corona & 0.77 \\
The curfew helps spread Corona & 0.77 \\
A person's strong immunity kills corona & 0.75 \\
Wearing a mask to prevent corona & 0.76 \\
The body's immunity can be raised & 0.76 \\
Fast food increases the body's immunity & 0.75 \\
Sterilization of materials to prevent corona & 0.71 \\
Remove the mask and wear it more than once to prevent corona & 0.79 \\
Washing hands with soap and water well, to prevent corona & 0.74 \\
\hline & 0.72 \\
\hline
\end{tabular}


It is evident from the results of the previous table that there are high correlation coefficients, with the lowest correlation coefficient reaching 0.71 and the highest correlation coefficient of 0.79 , and this indicates that the scale has a high degree of stability.

\section{The Result of the Study and Its Discussion}

To answer the study question that states "What is the level of awareness of people with learning disabilities about the Coronavirus pandemic and methods of prevention?" The percentages of the study sample responses were extracted, to determine their level of awareness and prevention, and Table No. (4) Shows the percentages of the sample responses for each phrase of the scale.

Table 4. Table title (The percentages of responses to the scale statements)

\begin{tabular}{|c|c|c|c|}
\hline \# & Statement & Yes & No \\
\hline 1 & Corona is an infectious disease & $100 \%$ & $0 \%$ \\
\hline 2 & Corona is a new disease & $72 \%$ & $28 \%$ \\
\hline 3 & Corona is a virus & $100 \%$ & $0 \%$ \\
\hline 4 & The number of viruses is small & $22 \%$ & $78 \%$ \\
\hline 5 & Viruses can be seen by eye & $6 \%$ & $94 \%$ \\
\hline 6 & Everyone is at risk of contracting Corona & $67 \%$ & $33 \%$ \\
\hline 7 & Corona stays in the body forever & $0 \%$ & $100 \%$ \\
\hline 8 & Corona is transmitted through the air & $28 \%$ & $72 \%$ \\
\hline 9 & Corona is transmitted by sneezing & $94 \%$ & $6 \%$ \\
\hline 10 & Corona leads to the death of every infected person & $11 \%$ & $89 \%$ \\
\hline 11 & You can recognize a person with corona & $22 \%$ & $78 \%$ \\
\hline 12 & You can catch corona without having symptoms & $72 \%$ & $28 \%$ \\
\hline 13 & There is a vaccine against Corona & $17 \%$ & $83 \%$ \\
\hline 14 & Coronavirus patient needs a long time to recover & $44 \%$ & $56 \%$ \\
\hline 15 & $\begin{array}{l}\text { Heat, sneezing and shortness of breath are symptoms of } \\
\text { Corona }\end{array}$ & $94 \%$ & $6 \%$ \\
\hline 16 & There is a treatment for Corona & $11 \%$ & $89 \%$ \\
\hline 17 & Corona can be prevented & $94 \%$ & $6 \%$ \\
\hline 18 & Distance from people, to prevent corona & $94 \%$ & $6 \%$ \\
\hline 19 & The curfew helps spread Corona & $28 \%$ & $72 \%$ \\
\hline 20 & A person's strong immunity kills corona & $89 \%$ & $11 \%$ \\
\hline 21 & Wearing a mask to prevent corona & $94 \%$ & $6 \%$ \\
\hline 22 & The body's immunity can be raised & $78 \%$ & $22 \%$ \\
\hline 23 & Fast food increases the body's immunity & $6 \%$ & $94 \%$ \\
\hline 24 & Sterilization of materials to prevent corona & $94 \%$ & $6 \%$ \\
\hline 25 & Remove the mask and wear it more than once to prevent corona & $22 \%$ & $78 \%$ \\
\hline 26 & Washing hands with soap and water well, to prevent corona & $100 \%$ & $0 \%$ \\
\hline 27 & Vegetables and vitamins increase the body's immunity & $100 \%$ & $0 \%$ \\
\hline
\end{tabular}

It is evident from the previous table that the most correct response reached $100 \%$ for five statements in the scale (1-3-7-26-27), which means that all members of the study sample (18 students) had correct responses to those five statements, the table also shows that the lowest correct response amounted to $56 \%$ for statement No. 14 in the scale, meaning that only 10 students answered a correct answer, and Table No. 5 shows the percentages of the results of students' responses to the two dimensions of the scale and the overall score. 
Table 5. Table title (The percentages of students' results)

\begin{tabular}{cccc}
\hline Student outcome & $\begin{array}{c}\text { After } \\
\text { awareness }\end{array}$ & $\begin{array}{c}\text { After } \\
\text { prevention }\end{array}$ & $\begin{array}{c}\text { Overall } \\
\text { grade }\end{array}$ \\
\hline First & $87 \%$ & $92 \%$ & $89 \%$ \\
Second & $93 \%$ & $92 \%$ & $93 \%$ \\
Third & $53 \%$ & $100 \%$ & $74 \%$ \\
Fourth & $93 \%$ & $100 \%$ & $96 \%$ \\
Fifth & $80 \%$ & $92 \%$ & $85 \%$ \\
Sixth & $93 \%$ & $83 \%$ & $89 \%$ \\
Seventh & $80 \%$ & $83 \%$ & $81 \%$ \\
Eighth & $93 \%$ & $100 \%$ & $96 \%$ \\
Ninth & $93 \%$ & $92 \%$ & $93 \%$ \\
Tenth & $87 \%$ & $92 \%$ & $89 \%$ \\
Eleventh & $93 \%$ & $92 \%$ & $93 \%$ \\
twelveth & $80 \%$ & $75 \%$ & $78 \%$ \\
Thirteenth & $80 \%$ & $83 \%$ & $81 \%$ \\
fourteenth & $53 \%$ & $58 \%$ & $56 \%$ \\
Fifteenth & $93 \%$ & $92 \%$ & $93 \%$ \\
sixteen & $100 \%$ & $92 \%$ & $96 \%$ \\
seventeenth & $73 \%$ & $83 \%$ & $78 \%$ \\
eighteen & $73 \%$ & $83 \%$ & $78 \%$ \\
Average students & $83 \%$ & $88 \%$ & $87 \%$ \\
\hline & & & \\
\hline & & $93 \%$ & 0 \\
\hline
\end{tabular}

It is clear from the previous table regarding the dimension of awareness, students' results as follows:

- Two cases with a very low level.

- Two intermediate level cases.

- 6 high level cases.

- 8 cases of very high level.

- The overall average of cases is within the high level.

It is also clear from the previous table regarding the prevention dimension, students' results as follows:

- Very low level case.

- Medium level case.

- 5 cases of high level.

- 11 cases, very high level.

- The overall average of cases is within the high level.

It is also clear from the previous table regarding the overall total of the scale, students' results as follows:

- Very low level case.

- 4 intermediate level cases.

- 6 high level cases.

- 7 cases with a very high level.

- The overall average of cases is within the high level.

The results showed high levels of people with learning disabilities in the two dimensions of the scale (awareness and prevention) and the overall score, as the results showed a high level of awareness of them about the emerging corona 
virus pandemic, as they are sufficiently aware of this epidemic and its severity and speed of spread among members of society, its symptoms, and its type. As well as the results also showed a high level in this group in how to prevent infection with Covid-19 disease or the transmission of the virus infection between individuals, and their knowledge of ways to increase the body's immunity, and their eagerness against the spread of the virus in society, and means of protection and prevention such as washing hands, social distancing and wearing a mask.

Despite the positive result shown by this study regarding the knowledge and awareness of people with learning disabilities about the emerging corona virus pandemic and methods of preventing it, this contradicts the concept of the state of learning difficulties and the characteristics associated with this category, as the researcher in this field knows very well the general disorders and deficiencies in the skills and abilities that those with learning difficulties suffer from, and the two researchers demonstrated the current study by reviewing previous studies of some of these disorders and deficiencies, such as the Al Thafiri study (2018), which showed the lack of competence, independence and belonging of this group, as well as the study of Al Thafiri and Abbas (2017), which showed shortcomings in their psychological compatibility. Likewise, their inability to form acceptable social behavior, as shown in the study of Nirit et al. (2005), and other previous studies that showed the different types of difficulties that this group suffers from, such as academic, developmental, or social difficulties.

The researchers attribute this result to a set of factors that helped and contributed to the emergence of this positive result in the knowledge of those with learning difficulties what is required to know about this pandemic, despite what they are suffering from as a result of their learning difficulties, and these factors are:

- Concentration and repetition of health information, through the various media outlets in the country, as well as information within the family and its continuous circulation, and the exchange of conversations and information among peers through various social media.

- The semi-permanent presence of all family members in the home is the latest type of following this category to apply the instructions.

- Exposing them to strange situations and events that they have not previously lived with, represented by government measures that have been implemented, such as the curfew, suspension of studies, and the closure of mosques, complexes, and entertainment places.

\section{Recommendations}

- The positive results of the current study that showed high levels of awareness of the Corona pandemic and ways to prevent exposure to infection, we should not forget the capabilities and characteristics of this group, so it is preferable to provide rehabilitation and guidance programs after the end of this problem and the return of normal life in educational institutions, in order to ensure that there is no future problems, as a result of this problem add to the problem of learning difficulties they suffer from.

- Work in the future through educational institutions working with people with learning difficulties to include the programs provided for this category to include programs for security and safety and prevention of risks and disasters.

- Providing guidance and qualification programs for parents of people with learning difficulties and those working with this group on how to deal with them in times of various risks and disasters.

- The positive results of the current study open the horizons for the participation of people with learning difficulties in serving the community by undertaking volunteer work and benefiting from them just like their ordinary peers.

\section{References}

Al Thafiri, N. (2010). Differences between tenth grade students with learning difficulties and their ordinary counterparts in social skills in the State of Kuwait. Journal of Childhood and Education, Faculty of Kindergarten, Alexandria University, 2(4), 107-160.

Al Thafiri, N. (2012). The relationship between social skills and psychological needs of tenth grade students in the State of Kuwait (a comparative study between ordinary students and those with learning difficulties). Journal of the Association of Arab Universities for Education and Psychology - Damascus University, 10(4), 65-93.

Al Thafiri, N. (2014). The effectiveness of a counseling program in improving social skills among a sample of adolescents with learning difficulties. Journal of Social Sciences, 42(4), 11-32.

Al Thafiri, N. (2015). A comparative study of the psychological needs of kindergarten children with developmental learning difficulties. Journal of Psychological and Educational Studies, Sultan Qaboos University, 9(3). 543-556. https://doi.org/10.24200/jeps.vol9iss3pp543-556 
Al Thafiri, N. (2016). The relationship of social and emotional learning difficulties to developmental and academic learning difficulties. International Conference on Special Education and Learning Difficulties, Al-Balqa Applied University, Amman, 22-24 March 2016.

Al Thafiri, N. (2018). Psychological needs is an introduction to early detection of pre-school developmental learning difficulties. International Journal of Educational and Psychological Studies, 4(3), 336-347.

Al Thafiri, N., \& Abbas, Z. (2017). Psychological compatibility among mentally superior students with learning difficulties. The Specialized Educational International Journal, 6(8), 107-115.

Kuwaiti Council of Ministers, World Health Organization,https://www.who.int/ar/emergencies/diseases/novel-coronavirus-2019/advice-for-public/q-a-coronavi ruses:26/5/2020

Manfredi, M., Crotti, N., Zain, A., \& Proverbio, A. (2012). Shooting the basket brain: Electrophysiological evidence for a similar semantic processing involved in language action visual perception. International Journal of Psychophysiology, 85(3), 386-394. https://doi.org/10.1016/j.jpsycho.2012.07.065

Nirit, B., Hany, S., \& Janice, M. (2005). Social Information Processing and Emotional Understanding in Children with Learning Disabilities. Journal of Learning Disabilities, 38(1), 45-61. https://doi.org/10.1177/00222194050380010401

Schum, N., Volker, H., \& Bianca, J. (2012). Some psychological variables among students with Learning Disabilities in academic skills, visual perception, motor and auditory. Journal of Experimental Child Psychology, 112(2), 161-177. https://doi.org/10.1016/j.jecp.2012.02.008

The Ministry of Health in the State of Kuwait (26 May 2020). Corona in Kuwait. https://corona.e.gov.kw/Ar/Home/NovelCoronavirus

\section{Copyrights}

Copyright for this article is retained by the author(s), with first publication rights granted to the journal.

This is an open-access article distributed under the terms and conditions of the Creative Commons Attribution license which permits unrestricted use, distribution, and reproduction in any medium, provided the original work is properly cited. 